\title{
Equilibrium, kinetic and thermodynamic studies of Reactive Red 120 dye adsorption by chitosan beads from aqueous solution
}

\author{
Nur Shazwani Abdul Mubarak ${ }^{2}$ Ali H. Jawad ${ }^{1,3} \cdot$ W. I. Nawawi ${ }^{1,3}$ \\ ${ }^{1}$ Coal and Biomass Energy Research Group, Faculty of Applied Sciences, Universiti Teknologi MARA, 40450 Shah Alam, Selangor, Malaysia \\ ${ }^{2}$ Faculty of Applied Sciences, Universiti Teknologi MARA, 40450 Shah Alam, Selangor, Malaysia \\ ${ }^{3}$ Coal and Biomass Energy Research Group, Faculty of Applied Sciences, Universiti Teknologi MARA, Arau Campus, 02600 Arau, Perlis, \\ Malaysia
}

Received: 13 March 2016/Revised: 11 May 2016/Accepted: 14 May 2016/Published online: 6 June 2016

(C) Joint Center on Global Change and Earth System Science of the University of Maryland and Beijing Normal University and Springer-Verlag Berlin Heidelberg 2016

\begin{abstract}
Chitosan beads (CHB) were prepared and studied in a batch mode operation for the adsorption of Reactive Red 120 dye from aqueous solution. Characterization on the surface of CHB was achieved by using point of zero charge $\left(\mathrm{pH}_{\mathrm{pzc}}\right)$ method, Fourier transform infrared spectroscopy, and scanning electron microscopy. Adsorbent dosage (0.02-1.5 g), initial $\mathrm{pH}$ solution (4-12), initial dye concentrations $(30-400 \mathrm{mg} / \mathrm{L})$, and contact time (2-500 $\mathrm{min})$ were used as the function to optimize the adsorption equilibrium experiments that were carried out during the course of this study. The adsorption equilibrium data show that the adsorption process obeys the Langmuir model with maximum adsorption capacities of 114.9, 123.5 and $129.9 \mathrm{mg} / \mathrm{g}$ for 303,313 and $323 \mathrm{~K}$, respectively. The kinetics of the RR 120 adsorption was wellfitted to the pseudo-second-order kinetics. Thermodynamic parameters such as standard Gibbs free energy $\left(\Delta G^{\circ}\right)$, standard enthalpy $\left(\Delta H^{\circ}\right)$ and standard entropy $\left(\Delta S^{\circ}\right)$ were determined. The positive value of enthalpy indicates that the uptake of RR 120 onto CHB is endothermic in nature. The results obtained supported the use of CHB as an effective as well as favorable adsorbent in treating RR 120 dye.
\end{abstract}

Keywords Chitosan · Adsorption · Reactive Red 120 . Beads

Ali H. Jawad

ahjm72@gmail.com

\section{Introduction}

Most of the textile, clothing, leather, cosmetics, paper, printing, and plastic industries use synthetic dyes as part of their production processes. However, the colored effluents might have comprised the synthetic dyestuff produced from these industries (Sharma et al. 2011). The synthetic dyes are classified as hazardous, toxic and nonbiodegradable as a result in restraining the photosynthesis activity by blocking the sunlight from penetrating into the water bodies. The exposure of colored substances to the environment even at trace levels is believed to be relatively risky for living things (Huang et al. 2013). Most of these dyes may also cause rigorous damage to humans such as dermatitis, cancer, jaundice, tumors, skin irritation, and heart defects (Alver and Metin 2012). Thus, it is essential to eliminate the hazardous compound in dyes from effluents before they can be discharged into the environment. It is important to select the most appropriate and suitable treatment method for the removal of dyes from wastewater by taking into consideration the source, composition and process of wastewater generation.

The existent of diverse treatment methods such as adsorption (Jawad et al. 2016a; Rashid et al. 2016), bioremediation (Khataee et al. 2012), electrochemical degradation (Fan et al. 2008), cation exchange membranes (Wu et al. 2008), Fenton chemical oxidation (Woo et al. 2014), and photocatalysis (Jawad et al. 2015, 2016b) had been extensively used for the past decades in removing dyes from aquatic bodies. Among these methods, adsorption received great attentions owing to its simplicity of design, high performance and convenient in operating without the production of dangerous end products 
(Rafatullah et al. 2010). Activated carbon is the most effective and efficient adsorbent for dye removal from aqueous effluents because of its organized pore structure and rational surface area that leads to high adsorption capacity. However, its high cost has motivated the search for inexpensive, locally available, and effective biosorbents (Sharma et al. 2011).

Among various biosorbents, chitosan has drawn a lot of attention of researches due to its content of amino and hydroxyl functional groups that act as highly active adsorption sites. Chitosan ( $\beta$ - $(1 \rightarrow 4)-2$-amino-2-deoxy-Dglucose) is a low cost biopolymer that has chemical characteristics such as nontoxic, heterogeneous, linear, cationic and biodegradable polysaccharide (Gupta 2009; Vakili et al. 2014). The chitosan backbone is a special biopolymer and has become benchmark of research material in various water treatment technologies attributable to the presence of free amino $\left(-\mathrm{NH}_{2}\right)$ and hydroxyl $(-\mathrm{OH})$ groups that act as adsorption sites (Auta and Hameed 2013, 2014). Given that the amino groups can be easily protonated in acidic solution, strong electrostatic attraction combined with higher adsorption affinity, especially toward an unlimited number of anionic dyes, can be achieved (Crini and Badot 2008; Nawi et al. 2010; Ngah et al. 2011; Vakili et al. 2014). However, natural chitosan is compressible at high operating pressure with high swelling index, and soluble in many organic acids (Rodrigues et al. 2008; Nawi et al. 2011).

Thus, physical modification of chitosan by converting chitosan powder and/or flakes into beads, film, and membrane is an important step to increase the surface area and porosity, resulting in improving the access to internal adsorption sites in the polymeric structure of chitosan (Miretzky and Cirelli 2009). Moreover, physical modification can also permit the polymer network to be expanded which enhances the diffusion of large size molecules and also reduce the crystalline state of the polymer (Azlan et al. 2009). Therefore, the aim of this work is to produce chitosan beads as a good and effective adsorbent for the removal of poly aromatic textile dyes with a high molecular weight like Reactive Red 120 (RR120).

\section{Materials and methods}

\subsection{Chemicals and materials}

The chitosan was purchased from Sigma-Aldrich with a monomer molecular weight of $322 \mathrm{~g} / \mathrm{mol}$. The Reactive Red 120 (RR 120) used in this work was obtained from Sigma-Aldrich molecular weight: $1469.34 \mathrm{~g} / \mathrm{mol}$; molecular formula: $\mathrm{C}_{44} \mathrm{H}_{24} \mathrm{Cl}_{2} \mathrm{~N}_{14} \mathrm{Na}_{6} \mathrm{O}_{20} \mathrm{~S}_{6} ; \lambda_{\text {max }}: 534 \mathrm{~nm}$. Analytical grade chemicals $\left(\mathrm{CH}_{3} \mathrm{COOH}, \mathrm{HCl}\right.$, and $\left.\mathrm{NaOH}\right)$ were purchased from R\&M Chemicals. All these chemicals were used directly without further purification. Ultra-pure water of $18.2 \mathrm{M} \Omega \mathrm{cm}^{-1}$ was used throughout this work.

\subsection{Adsorbate}

Stock solution of $1000 \mathrm{mg} \mathrm{L}^{-1}$ of RR120 was done by dissolving $1.0 \mathrm{~g}$ of RR120 powder with ultra-pure water in a 1-L volumetric flask. This stock solution was then diluted to obtain $30-400 \mathrm{mg} \mathrm{L}^{-1}$ initial concentration of dye which was used throughout the adsorption process. The molecular structure of RR 120 is shown in Fig. 1.

\subsection{Preparations and characterization of CHB}

Two grams of chitosan flakes was dissolved in $90 \mathrm{~mL}$ of $5 \%$ acetic acid solution. The viscous solution of chitosan was left with vigorous stirring using magnetic bar for $24 \mathrm{~h}$ until all the chitosan flakes were completely dissolved. The beads was formed by dropping the viscous chitosan solution using $10 \mathrm{~mL}$ syringe (TERUMO $10 \mathrm{cc} / \mathrm{mL}$ ) into $1000 \mathrm{~mL}$ of $0.05 \mathrm{M} \mathrm{NaOH}$ solution, and the beads were left stirring for $24 \mathrm{~h}$. The beads were washed using distilled water and dried for $24 \mathrm{~h}$ at room temperature. The dried beads were sieved to a constant size of $212 \mu \mathrm{m}$ before use. The $\mathrm{pH}_{\mathrm{pzc}}$ was analyzed by using a $\mathrm{pH}$ meter (Metrohm, Model 827 pH Lab, Switzerland). Fourier transform infrared (FTIR) spectrum analyses were recorded using PerkinElmer, Spectrum RX I spectroscope (4000-400 $\mathrm{cm}^{-1}$ ). The Surface properties of CHB before and after adsorption of RR 120 were observed by using scanning electron microscope, SEM, Leo Supra 50VP, Carl zeiss SMT instrument.

\subsection{Batch adsorption experiments}

The uptake of RR 120 onto CHB was investigated in a batch experiments. The experiments were carried out in a

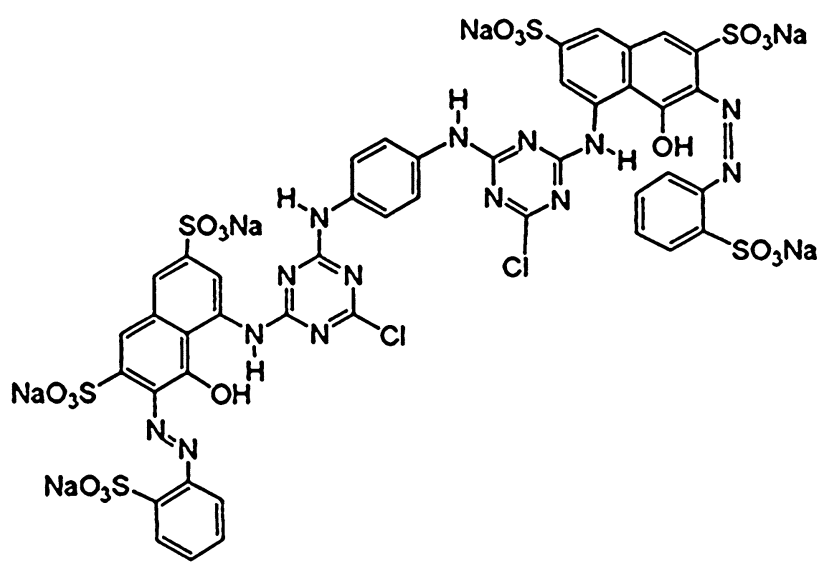

Fig. 1 Molecular structure of Reactive Red 120 dye 
sequence of 250-mL Erlenmeyer flask containing $100 \mathrm{~mL}$ RR 120 solution with different initial concentrations (30$400 \mathrm{mg} / \mathrm{L}$ ). Mass of adsorbent ranging from 0.02 to $1.5 \mathrm{~g}$ were added to the solution with $\mathrm{pH}$ varied from $\mathrm{pH} 4-12$ and were agitated with a shaking speed of 90 strokes/min and $303 \mathrm{~K}$ until equilibrium was reached (up to $500 \mathrm{~min}$ ) using a thermostat shaker (Memmert waterbath model WNB7-45, Germany). The pH of RR 120 was adjusted by using $0.10 \mathrm{M} \mathrm{NaOH}$ or $\mathrm{HCl}$. After shaking the samples, the adsorbent was separated by centrifuged (KUBOTA model 2800) at $2400 \mathrm{rpm}$ for $10 \mathrm{~min}$. The supernatants were later analyzed using UV spectrophotometer (model HACH DR2800). The dye uptake $q_{\mathrm{e}}(\mathrm{mg} / \mathrm{g})$ and the percent of color removal (\% CR) of RR 120 were determined using Eqs. (1) and (2), respectively.

$q_{\mathrm{e}}=\frac{\left(C_{0}-C_{\mathrm{e}}\right) V}{m}$

$C R \%=\frac{\left(C_{0}-C_{\mathrm{e}}\right)}{C_{\mathrm{o}}} \times 100$

where $C_{0}(\mathrm{mg} / \mathrm{L})$ and $C_{\mathrm{e}}(\mathrm{mg} / \mathrm{L})$ are the initial dye concentrations and the dye concentration at equilibrium, respectively. $V$ is the volume of the dye solution (L), and $m$ is the mass of adsorbent used ( $\mathrm{g}$ ). The adsorption experiments were conducted in duplicates and the results are reported as average.

\section{Results and discussion}

\subsection{Characterization of $\mathrm{CHB}$}

\subsection{1 $p H_{p z c}$ of $C H B$}

The point of zero charge $\left(\mathrm{pH}_{\mathrm{pzc}}\right)$ analysis was conducted to evaluate the charge-dependent state of CHB. The value of $\mathrm{pH}_{\mathrm{pzc}}$ for CHB was 7.05. From this observation, it can be concluded that the surface charge for $\mathrm{CHB}$ was classified as positively charged where the values of $\mathrm{pH}$ of the solution was lower than $\mathrm{pHpzc}$. At $\mathrm{pH}$ values below the $\mathrm{pH}_{\mathrm{pzc}}, \mathrm{CHB}$ adopts a positive charge of the surface because of the protonation of the amine groups $\left(-\mathrm{NH}_{2}\right)$ available on the surface of $\mathrm{CHB}$ and converts them into cationic groups $\left(-\mathrm{NH}_{3}{ }^{+}\right)$favoring the adsorption of anions (Nawi et al. 2010).

\subsubsection{FTIR spectral analysis}

FTIR analysis was performed for CHB as shown in Fig. 2a before and Fig. 2b after being contact with RR 120 dye solution. As observed in Fig. $2 \mathrm{a}$, the major peak at $3451 \mathrm{~cm}^{-1}$ can be attributed to the strong band vibration of $-\mathrm{OH}$ and $-\mathrm{NH}$ groups. $-\mathrm{CH}_{2}$ stretching appeared at

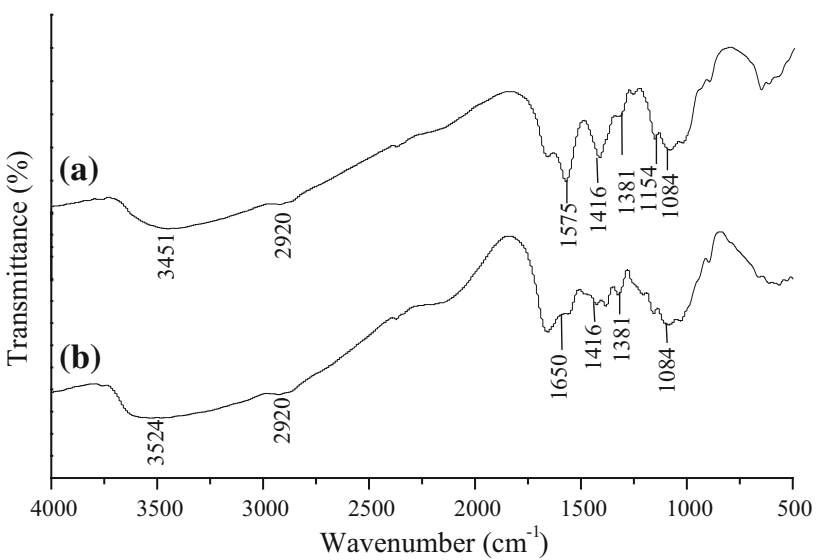

Fig. 2 FTIR spectra of a CHB before adsorption and b CHB after RR120 adsorption

$2920 \mathrm{~cm}^{-1}$ for asymmetric vibration meanwhile the peaks at around $1381 \mathrm{~cm}^{-1}$ and $1416 \mathrm{~cm}^{-1}$ are assigned to asymmetric deformation of $-\mathrm{CH}_{3}$ in amide group (Rusmin et al. 2015). The band depicted the skeletal vibrational stretch of $\mathrm{C}-\mathrm{O}$ in polysaccharide is obvious at $1084 \mathrm{~cm}^{-1}$ (Al-Sagheer and Merchant 2011). After adsorption of RR 120 as depicted in Fig. $2 b$, the amide bonds in chitosan show the characteristic of absorbance at $1650 \mathrm{~cm}^{-1}$ due to stretching of amide I $(\mathrm{C}=\mathrm{O})$. Other changes were seen at the absorbance band of $1575 \mathrm{~cm}^{-1}$ which corresponds to the interaction of $(\mathrm{C}-\mathrm{N})$ and $(\mathrm{C}-\mathrm{N}-\mathrm{H})$. On the other hand, the $\mathrm{C}-\mathrm{H}$ bond interaction due to amide II is evident at the peak of $1416 \mathrm{~cm}^{-1}$ where the peak deformed after adsorption (Deveci et al. 2015). The peak at $1154 \mathrm{~cm}^{-1}$ shows antisymmetric of C-O-C stretching (Martínez et al. 2004).

\subsubsection{Surface morphology of $C H B$}

The morphology images of before and after the adsorption of RR 120 onto CHB were analyzed and are presented in Fig. 3a, b respectively. The surface of CHB before adsorption is highly heterogeneous as illustrated in Fig. 3a. It is clearly visible that the cavities with different size and shape were spotted on the surface of CHB. The cavity structure is suitable for enhancing the adsorption of RR 120 within the structure of CHB. This statement can be strengthened by Fig. $3 b$ which shows clearly that the CHB surface has changed after the adsorption of RR 120 dye as evidenced by more dense and less cavities are seen on the surface of CHB.

\subsection{Batch adsorption studies}

\subsubsection{Effect of adsorbent dosage}

Different amounts of CHB dosage varying from 0.020 to $1.5 \mathrm{~g}$ were used to study the adsorption of RR 120 dye. The 

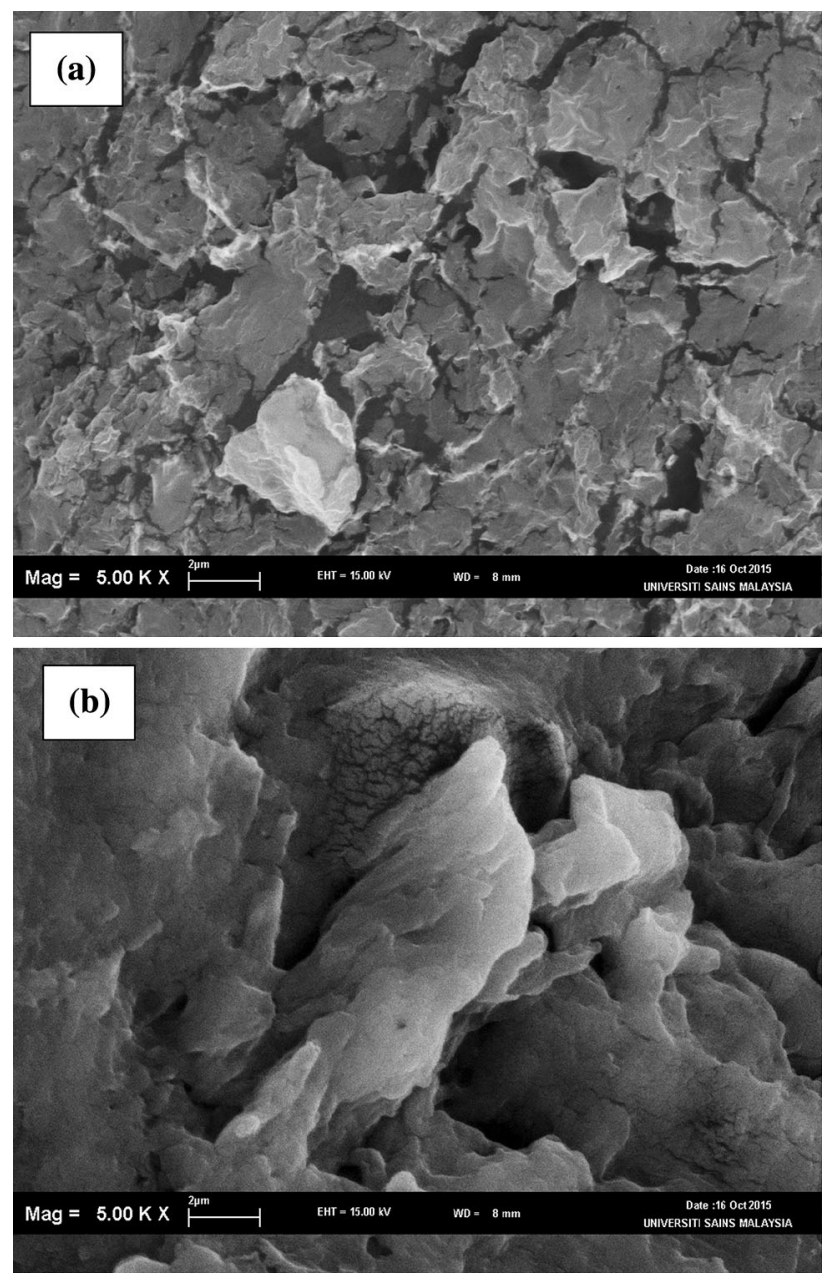

Fig. 3 SEM images of a CHB before adsorption and $\mathbf{b}$ CHB after RR120 adsorption

dependence of RR 120 adsorption on CHB was studied by incubating $100 \mathrm{~mL}$ of RR 120 solution with an initial dye concentration of $100 \mathrm{mg} / \mathrm{L}$ for a contact time of $180 \mathrm{~min}$ at $303 \mathrm{~K}$, a 90 strokes/min shaking speed, and normal $\mathrm{pH}$ of 5.22 for the initial RR 120 solution. Figure 4 shows the percentage of RR 120 removal increased from 19.5 to $95.8 \%$ by increasing the CHB dosage from 0.02 to $0.3 \mathrm{~g}$. As the dosage increases, the removal of RR 120 increases as well. This can be attributed to the availability of adsorption sites presented on the surface of the adsorbent. The highest amount of adsorbent dosage achieved for CHB was $0.30 \mathrm{~g} / 100 \mathrm{~mL}$ and was chosen as the optimal mass for the further investigations.

\subsubsection{Effect of solution $\mathrm{pH}$}

The initial $\mathrm{pH}$ for the adsorption of RR 120 dye was evaluated over a $\mathrm{pH}$ range of 4-12 as shown in Fig. 5. Based on the graph, the optimum uptake of RR 120 on the surface of

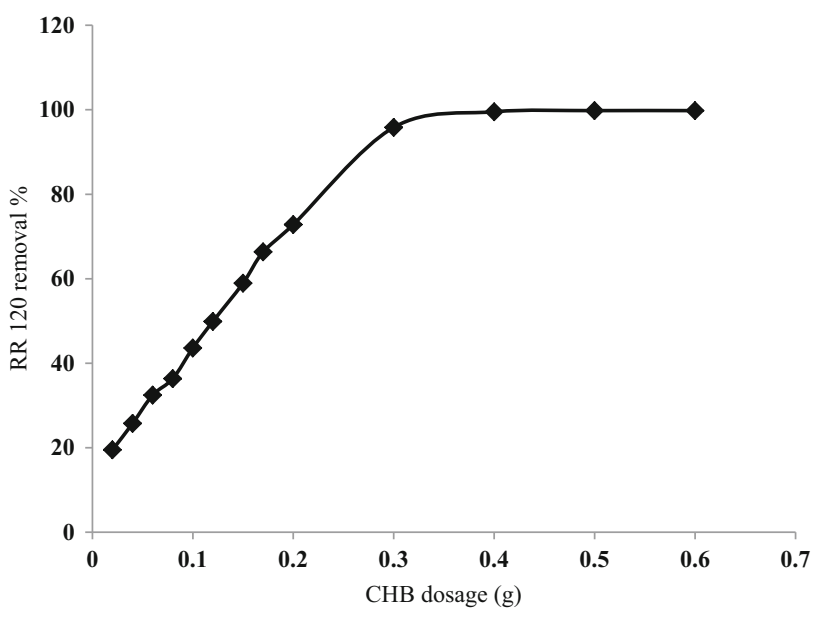

Fig. 4 Effect of adsorbent dosage on RR120 removal (\%) at initial $\mathrm{pH}$ of solution $=\mathrm{pH} 5.22$ (unadjusted), $[\mathrm{RR} 120]_{\mathrm{o}}$ dye $=100 \mathrm{mg} / \mathrm{L}$, volume of solution $=100 \mathrm{~mL}$, shaking speed $=90$ strokes $/ \mathrm{min}$ and contact time $=180 \mathrm{~min}$

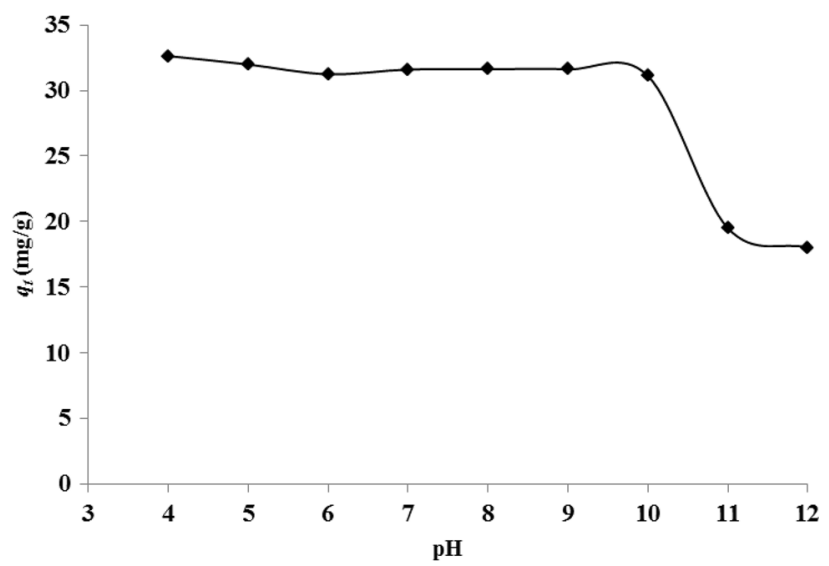

Fig. 5 Effect of initial pH on RR 120 removal ([RR120]。 dye $=100 \mathrm{mg} / \mathrm{L}$, amount of adsorbent $\mathrm{CH}: 0.3 \mathrm{~g}$, temperature: $303 \mathrm{~K}$, contact time: $180 \mathrm{~min}$, agitation speed $=90$ strokes and volume of solution $=100 \mathrm{~mL}$ )

CHB can be observed at acidic and neutral $\mathrm{pH}$ environments, whereas a sharp drop in adsorption can be observed at drastic basic environments of $\mathrm{pH}$ 11-12. This phenomenon can be explained by the interaction between the hydrogen atoms $\left(\mathrm{H}^{+}\right)$with amine groups $\left(-\mathrm{NH}_{2}\right)$ that may lead to the protonation of the $\mathrm{NH}_{2}$ functional group in chitosan. Consequently, at $\mathrm{pH}$ lower than $6.5\left(\mathrm{pH}<\mathrm{pH}_{\mathrm{pzc}}\right)$, the surface charge will become positive in acidic environment as expressed by Eq. (3). Thus, this phenomenon supports the result obtained by $\mathrm{pH}_{\mathrm{pzc}}$ analysis.

$\mathrm{R}-\mathrm{NH}_{2} \stackrel{\mathrm{H}^{+}}{\leftrightarrow} \mathrm{R}-\mathrm{NH}_{3}^{+}$

Additionally, by decreasing the $\mathrm{pH}$ value of dye solution, the intensity of the positive charge on the chitosan 
polymeric surface will be increased and making the sorption process $\mathrm{pH}$ sensitive (Chatterjee et al. 2005).

In aqueous solution, the sulfonate group from RR 120 dye is dissociated and is being converted to anionic dye ions as expressed in Eq. (4):

$\mathrm{RR} 120-\mathrm{SO}_{3} \mathrm{Na} \stackrel{\mathrm{H}_{2} \mathrm{O}}{\leftrightarrow} \mathrm{RR} 120-\mathrm{SO}_{3}^{-}+\mathrm{Na}^{+}$

Then, the adsorption process occurs due to the electrostatic interaction between positive charge on CHB surface and the negative charge of RR 120 dye. The equation is expressed as in Eq. (5).

$\mathrm{R}-\mathrm{NH}_{3}^{+}+\mathrm{RR} 120-\mathrm{SO}_{3}^{-} \leftrightarrow \mathrm{R}-\mathrm{NH}_{3}^{+} \mathrm{O}_{3} \mathrm{~S}-\mathrm{RR} 120$

A similar observation has been reported by Farzana and Meenakshi (2014) on the removal of toxic dyes using titanium dioxide impregnated chitosan beads. Therefore, $\mathrm{pH} 4.0$ was used as the $\mathrm{pH}$ value of RR 120 solution in this study.

\subsubsection{Effect of initial dye concentration and contact time}

The adsorption of RR 120 dye by CHB was investigated and plotted by the means of adsorption capacity versus contact time at initial RR120 concentration ranging from 30 to $400 \mathrm{mg} / \mathrm{L}$ as shown in Fig. 6. The RR 120 uptake increased rapidly with an increase in initial dye concentration as the amount of RR120 being adsorbed by CHB. As RR 120 concentrations increase, the collision rate between RR 120 molecules and CHB surface can be increased as well. Thus, more RR 120 anions were moved to the CHB surface. Longer contact time was needed to attend equilibrium at higher RR 120 concentration as there was a tendency for the RR 120 to pass deeper within the interior surface of the $\mathrm{CHB}$ and occupancy of more active adsorption sites available.

\subsection{Adsorption isotherms}

Adsorption isotherms explain the interaction between adsorbate with adsorbent, where it describes the interaction on how the dye molecules distribute between the bulk dye solution and the solid adsorbent once the system attended equilibrium state (Njoku et al. 2014). The linear Langmuir isotherm and Freundlich isotherm can be obtained from the equilibrium data. The Langmuir model (Langmuir 1918) describes monolayer adsorption processes for uniform adsorption sites, according to Eq. (6):

$\frac{C_{\mathrm{e}}}{q_{\mathrm{e}}}=\frac{1}{q_{\mathrm{m}} K_{\mathrm{L}}}+\frac{1}{q_{\mathrm{m}}} C_{\mathrm{e}}$

where $C_{\mathrm{e}}$ is the concentration $(\mathrm{mg} / \mathrm{L})$ of RR 120 at equilibrium time and $q_{\mathrm{e}}$ is the amount of RR 120 adsorbed per amount of adsorbent $(\mathrm{mg} / \mathrm{g}), K_{\mathrm{L}}$ is the Langmuir equilibrium constant, and $q_{\mathrm{m}}$ is the amount of RR 120 required to form a monolayer. Hence, a straight line with a slope $\left(1 / q_{\mathrm{m}}\right)$ and an intercept as $\left(1 / q_{\mathrm{m}} K_{\mathrm{L}}\right)$ can be obtained by plotting $C_{\mathrm{e}} / q_{\mathrm{e}}$ versus $C_{\mathrm{e}}$ as shown in Fig. 7.

The Freundlich model (Freundlich 1906) describes the multilayer adsorption isotherm onto heterogeneous adsorption sites, according to Eq. (7):

$\ln q_{\mathrm{e}}=\ln K_{\mathrm{F}}+\frac{1}{n_{\mathrm{F}}} \ln C_{\mathrm{e}}$

$K_{\mathrm{F}}$ and $n$ are Freundlich constants. $K_{\mathrm{F}}\left[\mathrm{mg} / \mathrm{g}(\mathrm{L} / \mathrm{mg})^{1 / n}\right]$ represents the adsorption capacity and $1 / n$ indicates the adsorption intensity and curvature. $K_{\mathrm{F}}$ and $n_{\mathrm{F}}$ can be

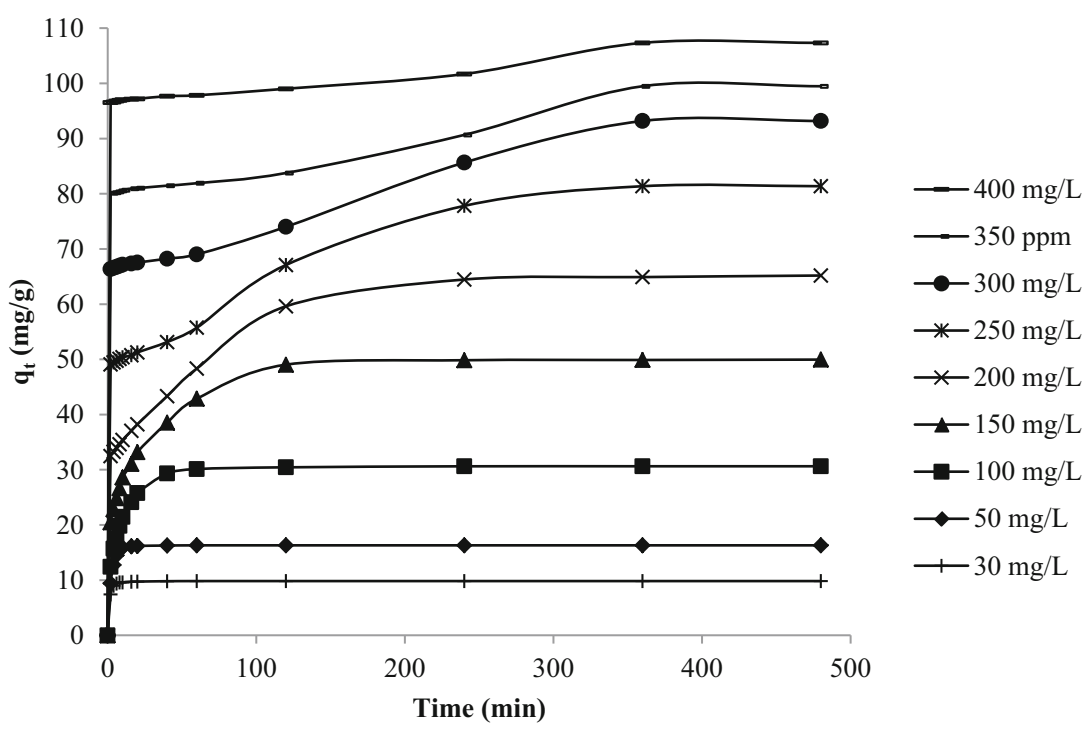

Fig. 6 Effect of initial dye concentration on the adsorption of RR120 dye (initial pH of solution = unadjusted, amount of $\mathrm{CH}$ adsorbent $=0.3 \mathrm{~g}$, temperature $=303 \mathrm{~K}$, agitation speed $=90$ strokes, and volume of solution $=100 \mathrm{~mL}$ ) 


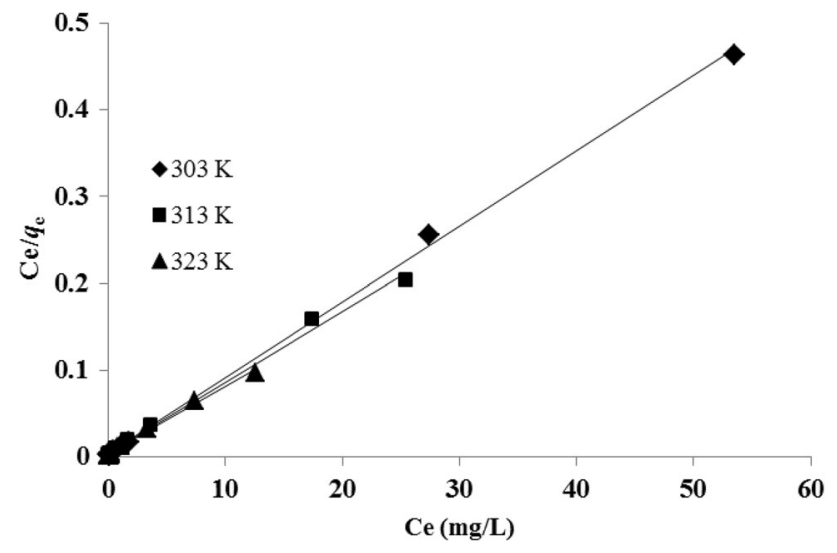

Fig. 7 Langmuir isotherm plots for the adsorption of RR120 onto $\mathrm{CHB}$ at variable temperatures

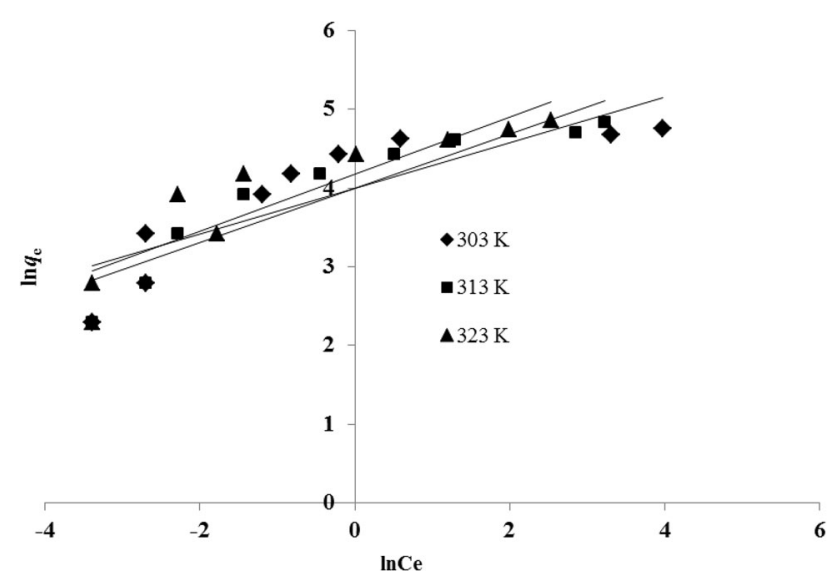

Fig. 8 Freundlich isotherm plots for the adsorption of RR120 onto $\mathrm{CHB}$ at variable temperatures

calculated from the intercept and slope of the plot of $\ln q_{\mathrm{e}}$ versus $\ln C_{\mathrm{e}}$ as shown in Fig. 8.

At the variable temperatures of 303,313 and $323 \mathrm{~K}$, the adsorption parameters for both models Langmuir and Freundlich are presented in Table 1. Based on the goodness-of-fit $R^{2}$ values, the adsorption of RR 120 onto CHB by the Langmuir model shows a better definition of the RR 120 adsorption. This implies that RR120 dye form a monolayer coverage on the homogeneous surface of the adsorbent that are energetically equivalent (Foo and Hameed 2012).

\subsection{Kinetics study}

The kinetic data were analyzed using two different kinetic models, namely pseudo-first-order (PFO) model and pseudo-second-order (PSO) model. The PFO model was suggested by (Lagergren 1898) and its linearized form is expressed by Eq. (8):
Table 1 Isotherm parameters for removal of RR120 onto CHB at various temperatures

\begin{tabular}{|c|c|c|c|}
\hline \multirow[t]{2}{*}{ Temperature $(\mathrm{K})$} & \multicolumn{3}{|c|}{ Langmuir isotherm } \\
\hline & $q_{\mathrm{m}}(\mathrm{mg} / \mathrm{g})$ & $K_{\mathrm{L}}(\mathrm{L} / \mathrm{mg})$ & $R^{2}$ \\
\hline 303 & 114.9 & 2.35 & 0.9989 \\
\hline 313 & 123.5 & 1.72 & 0.9955 \\
\hline \multirow[t]{3}{*}{323} & 129.9 & 2.20 & 0.9941 \\
\hline & \multicolumn{3}{|l|}{ Freundlich isotherm } \\
\hline & $K_{\mathrm{F}}\left[\mathrm{mg} / \mathrm{g}(\mathrm{L} / \mathrm{mg})^{1 / n}\right]$ & $1 / n$ & $R^{2}$ \\
\hline 303 & 54.3 & 3.44 & 0.7316 \\
\hline 313 & 54.3 & 2.90 & 0.8529 \\
\hline 323 & 65.1 & 2.75 & 0.8149 \\
\hline
\end{tabular}

$\ln \left(q_{\mathrm{e}}-q_{\mathrm{t}}\right)=\ln q_{\mathrm{e}}-\left(k_{1}\right) t$

where $q_{\mathrm{e}}(\mathrm{mg} / \mathrm{g})$ and $q_{\mathrm{t}}(\mathrm{mg} / \mathrm{g})$ are the amount of adsorbate adsorbed onto adsorbent at equilibrium and time $t$, respectively; while $k_{1}(1 / \mathrm{min})$ is the pseudo-first-order rate constant. From the slope of the plots of $\ln \left(q_{\mathrm{e}}-q_{\mathrm{t}}\right)$ versus $t$, the values of $k_{1}$ can be determined as shown in Fig. 9. The linear pattern of the PSO model (Ho and McKay 1998) is described by Eq. (9):

$\frac{t}{q_{\mathrm{t}}}=\frac{1}{k_{2} q_{\mathrm{e}}^{2}}+\frac{t}{q_{\mathrm{e}}}$

where $k_{2}(\mathrm{~g} / \mathrm{min} \mathrm{mg})$ is the rate constant of pseudo-secondorder model adsorption. The values of $k_{2}$ and $q_{\mathrm{e}(\mathrm{Theo})}$ were calculated from the intercept and slope of $t / q_{t}$ versus $t$, respectively, and are presented in Fig. 10. The kinetic data for the adsorption of RR120 onto CHB under various conditions were calculated from the related plots and are presented in Table 2. The linear regression coefficient, $R^{2}$ values obtained are favorable where the values of

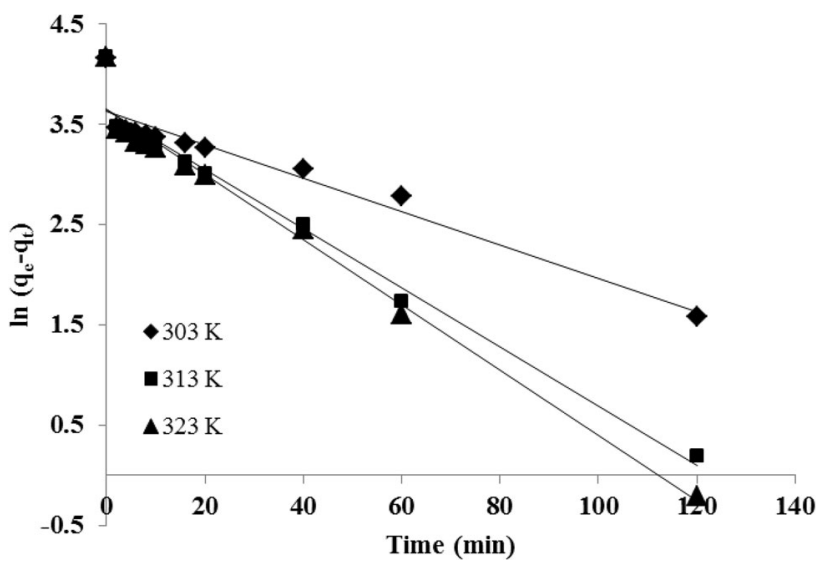

Fig. 9 Pseudo-first-order (PFO) kinetics of RR $120(200 \mathrm{mg} / \mathrm{L})$ adsorption on $\mathrm{CHB}$ at variable temperatures 


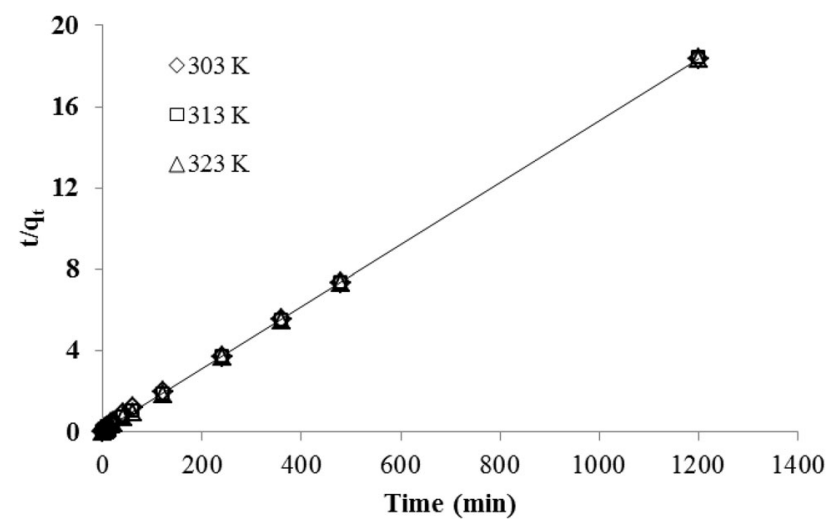

Fig. 10 Pseudo-second-order (PSO) kinetics of RR 120 (200 mg/L) adsorption on $\mathrm{CHB}$ at variable temperatures

Table 2 Pseudo-first-order and pseudo-second-order kinetic adsorption parameters applied to experimental data for the adsorption of RR120 on CHB at variable temperatures

\begin{tabular}{lccc}
\hline & \multicolumn{3}{l}{ Temperature $(\mathrm{K})$} \\
\cline { 2 - 4 } & 303 & 313 & 323 \\
\hline Pseudo-first order & 38.2 & 38.3 & 38.6 \\
$q_{\text {exp }}$ & 38.0 & 38.40 & 38.7 \\
$q_{\text {cal }}$ & 0.0167 & 0.0296 & 0.0326 \\
$k_{1}$ & 0.9038 & 0.9708 & 0.9754 \\
$R^{2}$ & & & \\
Pseudo-second order & 65.3 & 65.2 & 65.3 \\
$q_{\text {exp }}$ & 65.8 & 65.79 & 65.79 \\
$q_{\text {cal }}$ & 0.0017 & 0.0029 & 0.0031 \\
$k_{2}$ & 0.9996 & 0.9999 & 0.9999 \\
$R^{2}$ & & & \\
\hline
\end{tabular}

$R^{2} \geq 0.99$. This was also in line with the calculated values $q_{\mathrm{e}, \mathrm{cal}}$ obtained which are comparable to the experimental

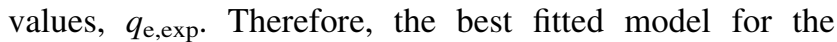
kinetic uptake of RR 120 onto CHB was the PSO model.

\subsection{Thermodynamics study}

The thermodynamic functions of adsorption of RR 120 onto $\mathrm{CHB}$ were calculated from the experimental results performed at 303, 313 and $323 \mathrm{~K}$. The changes in Gibbs free energy $\left(\Delta G^{\circ}\right)$, enthalpy $\left(\Delta H^{\circ}\right)$ and entropy $\left(\Delta S^{\circ}\right)$ were calculated using Eqs. (10-12) (Karaçetin et al. 2014):

$k_{\mathrm{d}}=\frac{q_{\mathrm{e}}}{C_{\mathrm{e}}}$

$\Delta G^{\circ}=-R T \ln k_{\mathrm{d}}$

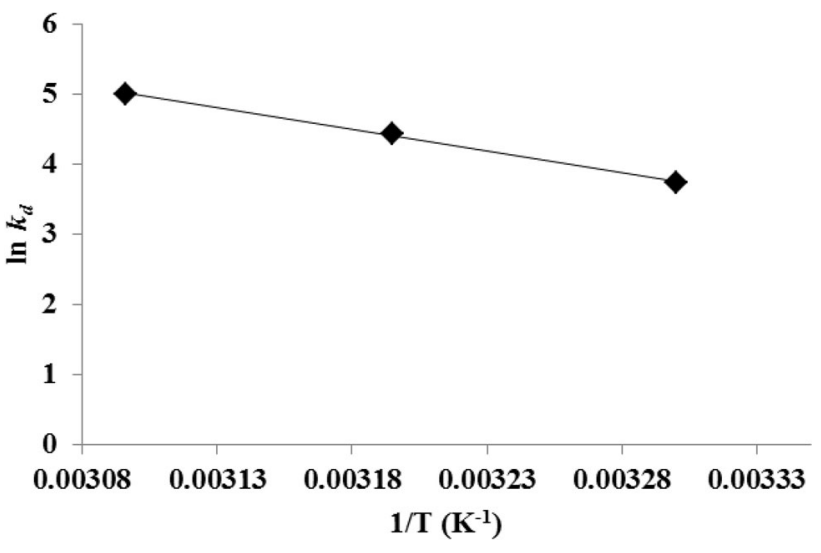

Fig. 11 Plot of $\ln K_{\mathrm{d}}$ versus $1 / T$ for estimation of thermodynamic parameters for the adsorption of RR120 onto $\mathrm{CHB}$

Table 3 Thermodynamic parameters for the adsorption of RR120 onto $\mathrm{CHB}$

\begin{tabular}{lccll}
\hline$T\left({ }^{\circ} \mathrm{C}\right)$ & $k_{\mathrm{d}}$ & $\begin{array}{l}\Delta G_{\mathrm{ads}}{ }^{\circ} \\
\left(\mathrm{kJ} \mathrm{mol}^{-1}\right)\end{array}$ & $\begin{array}{l}\Delta H_{\mathrm{ads}}{ }^{\circ} \\
\left(\mathrm{kJ} \mathrm{mol}^{-1}\right)\end{array}$ & $\begin{array}{l}\Delta S_{\mathrm{ads}}^{\circ} \\
\left(\mathrm{kJ} \mathrm{mol}^{-1}\right)\end{array}$ \\
\hline 303 & 41.623 & -9.39 & 51.68 & 0.2017 \\
313 & 83.580 & -11.15 & & \\
323 & 148.13 & -12.59 & & \\
\hline
\end{tabular}

$\ln k_{\mathrm{d}}=\frac{\Delta S^{\circ}}{R}-\frac{\Delta H^{\circ}}{R T}$

where $k_{\mathrm{d}}$ is the distribution coefficient, $q_{\mathrm{e}}$ is the concentration of RR 120 adsorbed on $\mathrm{CHB}$ at equilibrium $(\mathrm{mg} / \mathrm{L})$, $C_{\mathrm{e}}$ is the equilibrium concentration of RR120 in the liquid phase $(\mathrm{mg} / \mathrm{L}), \quad R$ is the universal gas constant $(8.314 \mathrm{~J} / \mathrm{mol} \mathrm{K})$, and $T$ is the absolute temperature $(\mathrm{K})$. The values of $\Delta H^{\circ}$ and $\Delta S^{\circ}$ were calculated from the slope and intercept of van't Hoff plots ( $\ln k_{\mathrm{d}}$ versus $\left.1 / T\right)$ as shown in Fig. 11, and the thermodynamic parameters are tabulated in Table 3. Positive value of the enthalpy change $\left(\Delta H^{\circ}=+51.68 \mathrm{~kJ} / \mathrm{mol}\right)$ is endothermic in nature which is consistent with the order of Langmuir adsorption capacity. Furthermore, this value also confirmed that the adsorption follows a chemisorption mechanism in nature involving strong forces of attractions (Yu et al. 2001; Gerçel et al. 2007). On the other hand, negative value for adsorption standard free energy change $\Delta G^{\circ}$ and a positive standard entropy change $\Delta S^{\circ}$ indicate that the process is a spontaneous process. The positive value of $\Delta S^{\circ}$ also confirms a high preference of RR120 molecules for the surface of $\mathrm{CHB}$ and also suggests the possibility of some structural changes or readjustments in the dye-CHB adsorption complex. 


\section{Conclusions}

In this work, chitosan powder was converted into beads form and successful study was completed for the adsorption of RR 120 dye from aqueous solution. Adsorption equilibrium experiments were performed as a function of adsorbent dosage, $\mathrm{pH}$, initial dye concentration and contact time. CHB showed the highest adsorption capacity for RR 120 dye at $\mathrm{pH}$ 4. Meanwhile, the optimum adsorbent dosage was $0.3 \mathrm{~g}$. Langmuir isotherm showed better correlation coefficient as compared to Freundlich model with adsorption capacity, $q_{\max }$ of 114.9 , 123.5 and $129.9 \mathrm{mg} / \mathrm{g}$ for 303,313 and $323 \mathrm{~K}$, respectively. It was found that the study fits pseudo-secondorder equation and was the best in describing the adsorption kinetics of RR 120 on CHB. Thermodynamics calculation denotes that the adsorption process was spontaneous and endothermic in nature.

Acknowledgments The authors thank the Faculty of Applied Sciences, Universiti Teknologi MARA, for facilitating this work. We would like also to acknowledge Malaysian Ministry of Higher Education (Kementerian Pendidikan Tinggi Malaysia) for the MyBrain scheme for funding Nur Shazwani Abdul Mubarak.

\section{References}

Al-Sagheer F, Merchant S (2011) Visco-elastic properties of chitosan-titania nano-composites. Carbohydr Polym 85:356-362

Alver E, Metin AÜ (2012) Anionic dye removal from aqueous solutions using modified zeolite: adsorption kinetics and isotherm studies. Chem Eng J 200:59-67

Auta M, Hameed B (2013) Coalesced chitosan activated carbon composite for batch and fixed-bed adsorption of cationic and anionic dyes. Colloids Surf B 105:199-206

Auta M, Hameed B (2014) Chitosan-clay composite as highly effective and low-cost adsorbent for batch and fixed-bed adsorption of methylene blue. Chem Eng J 237:352-361

Azlan K, Saime WNW, Liew L (2009) Chitosan and chemically modified chitosan beads for acid dyes sorption. J Environ Sci 21:296-302

Chatterjee S, Chatterjee S, Chatterjee BP, Das AR, Guha AK (2005) Adsorption of a model anionic dye, eosin $\mathrm{y}$, from aqueous solution by chitosan hydrobeads. J Colloid Interface Sci 288:30-35

Crini G, Badot P-M (2008) Application of chitosan, a natural aminopolysaccharide, for dye removal from aqueous solutions by adsorption processes using batch studies: a review of recent literature. Prog Polym Sci 33:399-447

Deveci I, Doğaç YI, Teke M, Mercimek B (2015) Synthesis and characterization of chitosan/ $/ \mathrm{TiO}_{2}$ composite beads for improving stability of porcine pancreatic lipase. Appl Biochem Biotechnol 175:1052-1068

Fan L, Zhou Y, Yang W, Chen G, Yang F (2008) Electrochemical degradation of aqueous solution of amaranth azo dye on ACF under potentiostatic model. Dyes Pigm 76:440-446

Farzana MH, Meenakshi S (2014) Photo-decolorization and detoxification of toxic dyes using titanium dioxide impregnated chitosan beads. Int J Biol Macromol 70:420-426
Foo K, Hameed B (2012) Coconut husk derived activated carbon via microwave induced activation: effects of activation agents, preparation parameters and adsorption performance. Chem Eng J 184:57-65

Freundlich H (1906) Ueber die adsorption in Loesungen (adsorption in solution). Z Phys Chem 57:385-470

Gerçel Ö, Özcan A, Özcan AS, Gercel HF (2007) Preparation of activated carbon from a renewable bio-plant of Euphorbia rigida By $\mathrm{H}_{2} \mathrm{SO}_{4}$ activation and its adsorption behavior in aqueous solutions. Appl Surf Sci 253:4843-4852

Gupta V (2009) Application of low-cost adsorbents for dye removal-a review. J Environ Manage 90:2313-2342

Ho Y-S, Mckay G (1998) Sorption of dye from aqueous solution by peat. Chem Eng J 70:115-124

Huang R, Liu Q, Huo J, Yang B (2013) Adsorption of methyl orange onto protonated cross-linked. Arab J Chem. doi:10.1016/j.arabjc. 2013.05.017

Jawad AH, Alkarkhi AF, Mubarak NSA (2015) Photocatalytic decolorization of methylene blue by an immobilized $\mathrm{TiO}_{2}$ film under visible light irradiation: optimization using response surface methodology (RSM). Desalination Water Treat 56:161-172

Jawad AH, Mubarak NSA, Ishak MAM, Ismail K, Nawawi W (2016a) Kinetics of photocatalytic decolourization of cationic dye using porous $\mathrm{TiO}_{2}$ film. J Taibah Univ Sci 10:352-362

Jawad AH, Rashid RA, Ishak MAM, Wilson LD (2016b) Adsorption of methylene blue onto activated carbon developed from biomass waste by $\mathrm{H}_{2} \mathrm{SO}_{4}$ activation: kinetic, equilibrium and thermodynamic studies. Desalination Water Treat. doi:10.1080/ 19443994.2016.1144534

Karaçetin G, Sivrikaya S, Imamoğlu M (2014) Adsorption of methylene blue from aqueous solutions by activated carbon prepared from hazelnut husk using zinc chloride. J Anal Appl Pyrol 110:270-276

Khataee A, Movafeghi A, Torbati S, Lisar SS, Zarei M (2012) Phytoremediation potential of duckweed (Lemna minor L.) in degradation of CI Acid Blue 92: artificial neural network modeling. Ecotoxicol Environ Saf 80:291-298

Lagergren S (1898) Zur theorie der sogenannten adsorption gelöster stoffe, Kungliga Svenska Vetenskapsakademiens. Handlingar 24(4):1-39

Langmuir I (1918) The adsorption of gases on plane surfaces of glass, mica and platinum. J Am Chem Soc 40:1361-1403

Martínez Y, Retuert J, Yazdani-Pedram M, Cölfen H (2004) Hybrid ternary organic-inorganic films based on interpolymer complexes and silica. Polymer 45:3257-3265

Miretzky P, Cirelli AF (2009) Hg (II) removal from water by chitosan and chitosan derivatives: a review. J Hazard Mater 167:10-23

Nawi M, Sabar S, Jawad A, Ngah WW (2010) Adsorption of Reactive Red 4 by immobilized chitosan on glass plates: towards the design of immobilized $\mathrm{TiO}_{2}$-chitosan synergistic photocatalystadsorption bilayer system. Biochem Eng J 49:317-325

Nawi M, Jawad AH, Sabar S, Ngah WW (2011) Photocatalyticoxidation of solid state chitosan by immobilized bilayer assembly of $\mathrm{TiO}_{2}$-chitosan under a compact household fluorescent lamp irradiation. Carbohydr Polym 83:1146-1152

Ngah WW, Teong L, Hanafiah M (2011) Adsorption of dyes and heavy metal ions by chitosan composites: a review. Carbohydr Polym 83:1446-1456

Njoku V, Foo K, Asif M, Hameed B (2014) Preparation of activated carbons from rambutan (Nephelium lappaceum) peel by microwave-induced $\mathrm{KOH}$ activation for acid yellow 17 dye adsorption. Chem Eng J 250:198-204

Rafatullah M, Sulaiman O, Hashim R, Ahmad A (2010) Adsorption of methylene blue on low-cost adsorbents: a review. J Hazard Mater 177:70-80 
Rashid RA, Jawad AH, Ishak MAM, Kasim NN (2016) KOHactivated carbon developed from biomass waste: adsorption equilibrium, kinetic and thermodynamic studies for methylene blue uptake. Desalination Water Treat. doi:10.1080/19443994. 2016.1167630

Rodrigues AC, Boroski M, Shimada NS, Garcia JC, Nozaki J, Hioka N (2008) Treatment of paper pulp and paper mill wastewater by coagulation-flocculation followed by heterogeneous photocatalysis. J Photochem Photobiol, A 194:1-10

Rusmin R, Sarkar B, Liu Y, Mcclure S, Naidu R (2015) Structural evolution of chitosan-palygorskite composites and removal of aqueous lead by composite beads. Appl Surf Sci 353:363-375

Sharma P, Kaur H, Sharma M, Sahore V (2011) A review on applicability of naturally available adsorbents for the removal of hazardous dyes from aqueous waste. Environ Monit Assess 183:151-195

Vakili M, Rafatullah M, Salamatinia B, Abdullah AZ, Ibrahim MH, Tan KB, Gholami Z, Amouzgar P (2014) Application of chitosan and its derivatives as adsorbents for dye removal from water and wastewater: a review. Carbohydr Polym 113:115-130

Woo YS, Rafatullah M, Al-Karkhi AFM, Tow TT (2014) Removal of Terasil Red $\mathrm{R}$ dye by using Fenton oxidation: a statistical analysis. Desalination Water Treat 52:4583-4591

Wu J-S, Liu C-H, Chu KH, Suen S-Y (2008) Removal of cationic dye methyl violet $2 \mathrm{~B}$ from water by cation exchange membranes. J Membr Sci 309:239-245

Yu Y, Zhuang Y-Y, Wang Z-H (2001) Adsorption of water-soluble dye onto functionalized resin. J Colloid Interface Sci 242:288-293 